Insight, part of a Special Feature on Do we need new management paradigms to achieve sustainability in tropical forests?

\title{
Assessing Sustainability of Logging Practices in the Congo Basin's Managed Forests: the Issue of Commercial Species Recovery
}

\author{
$\underline{\text { Alain Karsenty }}^{1}$ and Sylvie Gourlet-Fleury ${ }^{1}$
}

\begin{abstract}
Traditionally, sustained yield (SY) has been viewed as a pillar of sustainable forest management (SFM), but this has been increasingly questioned. Ensuring SY of some species, i.e., a "strong sustainability" paradigm, could be an inadequate criterion if consideration of the social and economic components of the SFM concept are desired. SFM was translated into the ATO/ITTO set of principles, criteria, and indicators (PCI) for forest management in the Congo Basin; it resulted in the necessity for a certified logging company to ensure that no significant change in structure and floristic composition would result from logging operations. Besides raising the question of where to place the change threshold, we argue that sustainability must be considered from three indissociable viewpoints: ecological, social, and economic. The issue is how to balance these criteria, knowing that this assessment will involve potential conflicts of representations and beliefs. To discuss these questions, we used the example of two heavily logged timber species in the Congo Basin, sapelli (Entandrophragma cylindricum) and ayous (Triplochiton scleroxylon). Using long-term data collected from permanent sample plots in M'Baiki, Central African Republic, we calibrated a matrix model and performed short- and long-term simulations to examine (1) the potential effect of repeated logging of the species under the current national regulation system and (2) the rules that should be set to reach long-term SY. Ensuring long-term SY would require a $22 \%$ and $53 \%$ decrease in the felling intensity of E. cylindricum and T. scleroxylon, respectively, at first cut, together with an increase in overall logging intensity targeted toward less-used species. Light-demanding E. cylindricum and T. scleroxylon require open forests to regenerate and grow. This new set of rules is probably economically unsustainable for the current African forest industry, and will not meet the ecological requirements encapsulated in the ATO/ITTO PCI. We thus stress the following points: (1) the importance of most exploited species for the current industry may change as wood processing capacities become more efficient and markets change, potentially providing conditions for harvesting a greater number of species; (2) floristic change is unavoidable in these conditions, but this problem should be addressed at a broad scale, notably by ensuring a network of protected areas; (3) as long as the timber industry remains one of the few sources of employment and revenues in marginalized countries, reducing SFM to SY of the most exploited species on every concession appears questionable.
\end{abstract}

Key Words: Congo Basin; criteria and indicators; silviculture systems; sustainable forest management; sustainable yield management; tropical forests

\section{INTRODUCTION}

Is the last generation of tropical forest management plans sustainable? Given that models of forest dynamics are providing increasingly accurate results regarding timber recovery with time after harvesting, will it become easier to assess the sustainability of tropical forest management regimes on a consensual basis?
In a stimulating paper, Luckert and Williamson (2005) ask whether sustained yield (SY) should be considered necessary for sustainable forest management, and argue that "with SY policies, we have probably chosen to attach strong sustainability policies to the only forest resource that does not need such protection (i.e., timber), while we have excluded other resources that could well need such protection (e.g., biodiversity) for pursuing SFM 
[sustainable forest management]." Strong sustainability implies placing constraints on the reduction of stocks of natural capital to prevent irreversibility (non-substitutability between natural and capital assets), whereas weak sustainability may allow a decrease in stocks of natural capital, as long as levels of total capital (including human-made) are maintained. Luckert and Williamson (2005) suggest removing the prescribed annual allowable cut, which is designed to ensure SY, from the framework of SFM plans in favor of safe minimum standards "on components of forest capital that are subject to irreversibility and (or) that have public good features." The question of the necessity of SY is critical for tropical silviculture and management plan prescriptions in the tropics, where initial logging often takes place in primary forests with over-mature trees, and where felling cycles (in a properly managed forest) rarely exceed 30-40 years. Criteria and indicators likely to be used as a basis for certification in the tropics are sometimes very precise on this issue. For instance, amongst the ATO/ITTO (2003) set of principles, criteria, and indicators (PCI) for production forest management in Africa, Indicator 3.3.4 states " $[\mathrm{t}]$ he diversity and density of flora species are not significantly modified by harvesting," and "[t]he forest structure is similar before and after harvesting" (Subindicator 3.2.2.3.). Both clearly reflect a strong sustainability perspective.

Because this set of PCI is likely to be used in major certification schemes, and because numerous management plans are beginning to be implemented in central African countries (Gabon, Congo, Cameroon, Central African Republic), it is worth examining the projections of timber recovery for the first and subsequent felling cycles made by recent dynamics models, based on field data. These projections should be discussed within the perspective of sustainability, with different understandings attached to the concept of sustainability (weak, strong, etc.), and with regard to its three distinct, yet connected, aspects: social, ecological, and economic. Here, we discuss how to address this issue in a tropical forestry context, and point out in what respect the question, "is it sustainable?" cannot be answered without a preliminary reflection on the values that each person places on the sustainability concept itself, making a consensus on the matter rather unlikely.

\section{What is at stake?}

The central question is whether it is possible to reconcile a long-term supply of timber with longterm preservation of all ecological functions and processes of the forest, and above all, biodiversity. There is considerable debate on this point. Some authors (Rice et al. 1997, Bawa and Seidler 1998) argue that management of natural tropical forests cannot at the same time (1) be compatible with the maintenance of biodiversity, (2) be economically viable, and (3) result in long-term sustained timber yields. On the other hand, Pearce et al. (2003) suggest that this is possible under certain circumstances. Whereas Rice et al. (2001) argue in favor of a log-and-protect strategy, with an initial selective logging, followed by outright protection, Fredericksen and Putz (2003) claim that intensive silviculture in production forests should not be discouraged, and that in many places, this is the only way of ensuring the regeneration of valuable species, keeping loggers on restricted areas and making forestry a profitable activity.

Considering tree species, at least one fact can be acknowledged: It is impossible for a primary forest to quickly recover all the aspects of its initial state after logging. Because the standing volume that is first logged "has accumulated over a long period, the commercial timber is likely to be of a quality and volume that will probably not be matched in future cuts ... unless the logged forest is closed to further exploitation for a century or more. In this sense the first crop is, in practical terms, not repeatable" (Poore et al. 1989). The shift in structure and floristic composition is unavoidable; heliophilous species are favored by the opening of the stands and greater light availability. As a consequence, floristic alpha-diversity may temporarily increase as predicted by the intermediate disturbance theory (Connell 1978) and demonstrated, for example, by Molino and Sabatier (2001). But, there is a risk that, under short and repeated felling cycles, rare shade-tolerant species will be lost. Floristic diversity at the regional level could decrease because of the floristic homogenization of logged forests (Bawa and Seidler 1998). 


\section{SIMULATION MODEL OF SINGLE- SPECIES RECOVERY AFTER LOGGING}

\section{General features}

As data accumulate on permanent sample plots in various tropical forest sites, more is known about the behavior of particular species in undisturbed compared to disturbed stands. Models can be calibrated to determine, on a quantifiable basis, what the stand (or at least particular populations) will look like several years after logging. As illustrations, we focused on two important commercial species logged in the forests of the Central African Republic, namely sapelli (Entandrophragma cylindricum; Meliaceae) and ayous (Triplochiton scleroxylon; Sterculiaceae). Using long-term observations (19years), the quality of the predictions made by simple matrix models over time-periods compatible with felling cycles currently used in tropical countries (25-40 years) can be illustrated (Fig. 1). These models can predict what will remain in the forest at the end of the first felling cycle with reasonable confidence, depending on the management rules adopted. We examined model predictions for $E$. cylindricum and $T$. scleroxylon at two sites in the Central African Republic: the M'Baïki experimental site (Bedel et al. 1998) and a nearby forest under concession (Table 1). In M'Baiki, no more than $16 \%$ and $30 \%$ of the exploitable trees of E. cylindricum and $T$. scleroxylon, respectively, could be recovered within the first felling cycle.

Predictions depend on the matrix parameters, and thus, on the data set used to compute them (here, the data from M'Baiki). They also greatly depend, for a given set of parameters, on the characteristics of the diameter-class structure of the population studied; whereas E. cylindricum accumulated a great number of large trees on the M'Baiki site, this was not the case in the forest concession, where the number of large trees was 4.5 times lower (Table $1)$. In the concession, the number of trees in intermediate classes, potentially future crop trees, was sufficient to ensure a recovery of $50 \%$ of the volume at the end of the first cycle.

An important point is to evaluate whether the levels of recovery are sustainable from a biological point of view. A possible way to examine this is to simulate the evolution of the populations of interest under a repeated felling regime reproducing the parameters of the first logging. In all cases, these logging rules led to a decrease in the exploitable stock of trees (Fig. 2 and Table 1, for the 10th cycle) because of a decrease in the populations as a whole; half the population of trees $\geq 10 \mathrm{~cm}$ in $\mathrm{dbh}$ was lost within five cycles for E. cylindricum, and even more quickly for T. scleroxylon. A possible conclusion is that such regimes are biologically unsustainable over the intermediate to long term if the objective is to manage the stand under a sustained yield regime.

Among many potential solutions to approximate a sustained yield regime (e.g., cut once, change species for the second cut, and then cut the initial species on the third felling cycle), one is to reduce the felling intensity at the first cut; models can quickly help establish a suitable intensity, i.e., that stabilizes the recovery of the exploited volume over time. For E. cylindricum and T. scleroxylon, the targeted intensity would be $70 \%$ and $45 \%$ of the number of standing trees $\geq$ the diameter cutting limit (DCL), respectively (Table 1). If economic sacrifices are important at the first cut (Table 1, compare the volume to be logged at first cut in the actual system with the mean volume logged in the sustainable system), the mean volume harvestable over the long-term should generally be higher than in the current system (Table 1, compare the mean volumes to be logged per cycle in the two systems).

\section{Limits of the simulations}

Our simulations are based on various hypotheses, some of which must be examined seriously. First, the stands are opened by relatively high overall logging intensities or silvicultural operations to stimulate increments in tree diameter. Second, the data used to calibrate the parameters of the matrix models are representative of the species' behavior in both space and time. However, there is no reason why the parameters should not change with the physical characteristics of the site (M'Baïki versus the nearby forest concession), climate (rainy versus dry years, climate changes at the scale of several felling cycles), or local stand density.

The most limiting factor is the lack of knowledge of regeneration processes. The only information available from most permanent sample plots and most species is recruitment of individuals $\geq 10 \mathrm{~cm}$ in dbh. Recruitment events, like mortality events, are infrequent, and thus, difficult to model. Moreover, newly recruited trees cannot be linked to 
Fig. 1. Evolution of the number of exploitable trees after logging for two important commercial species (Entandrophragma cylindricum and Triplochiton scleroxylon) in the Central African Republic (CAR). Predictions were made using a stochastic matrix model calibrated with data from the M'Baïki experimental site in the CAR (methods are described in Gourlet-Fleury et al. 2004, 2005), and were compared to long-term observations from this site.
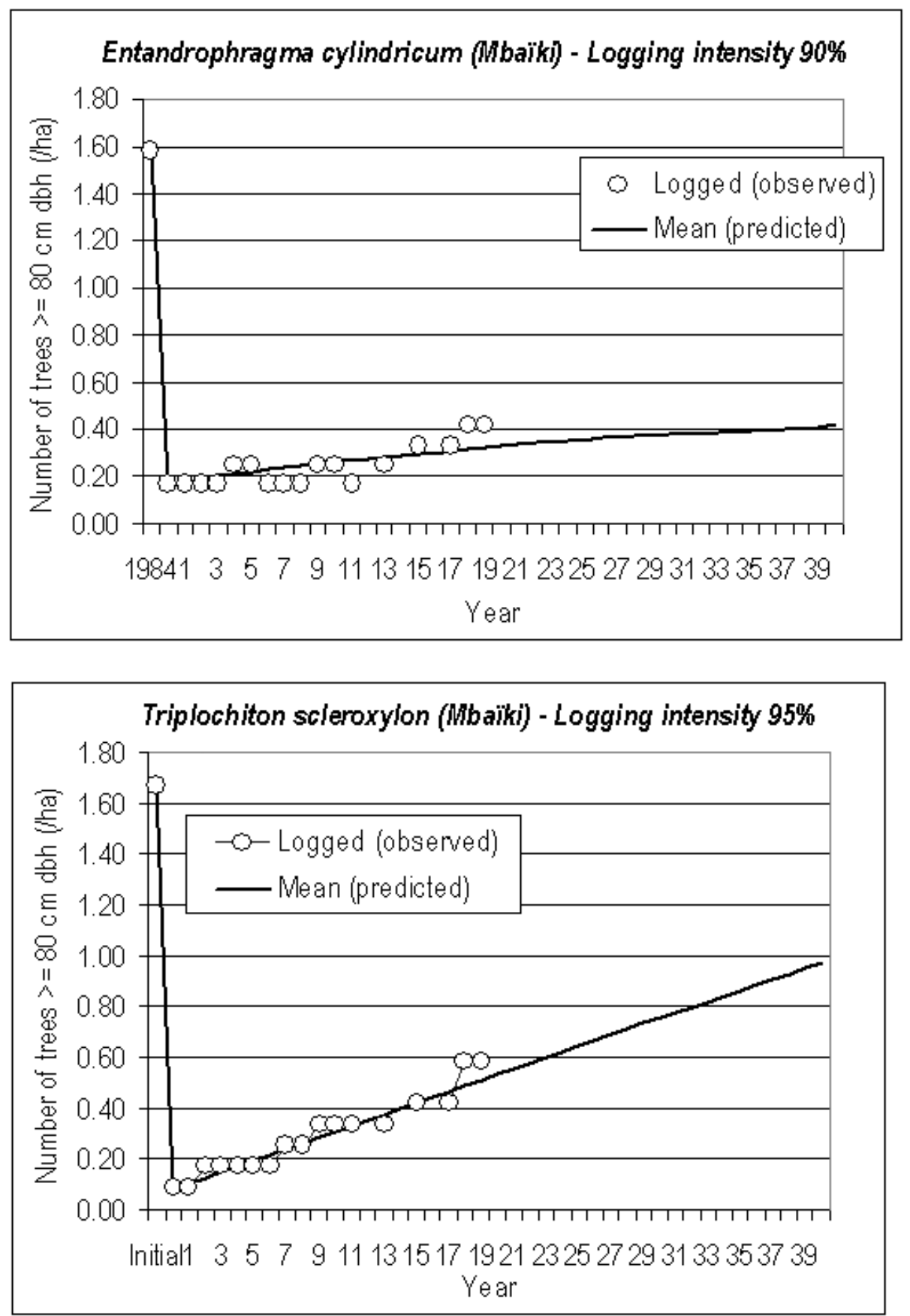
Table 1. Evolution of the exploitable stock of two main commercial species logged in the Central African Republic (CAR; Entandrophragma cylindricum and Triplochiton scleroxylon) under the current felling regime.

\begin{tabular}{|c|c|c|c|c|c|c|}
\hline \multirow[t]{2}{*}{ Species and logging rules } & \multicolumn{5}{|c|}{ Actual rules } & Sustainable system \\
\hline & $\begin{array}{l}\text { Logged (in- Recovered } \\
\text { dividuals/ha } \geq \text { after } 1 \text { cycle } \\
\text { DCL) at } \\
\text { first cut }\end{array}$ & $\begin{array}{c}\text { Recovered } \\
(\%)\end{array}$ & $\begin{array}{l}\text { Logged (i- } \\
\text { ndividuals/ } \\
\text { ha) at } \\
\text { cycle } 10\end{array}$ & $\begin{array}{l}\text { Mean logged } \\
\text { per cycle, } \\
\text { for } 10 \\
\text { cycles }\end{array}$ & $\begin{array}{l}\text { Proportion of } \\
\text { stock removal } \\
\text { at each } \\
\text { cycle } \dagger\end{array}$ & $\begin{array}{lc}\text { Logged (i- } & \text { Mean logged } \\
\text { ndividuals/ } & \text { in stabilized } \\
\text { ha } \geq \text { DCL) } & \text { system, per } \\
\text { at first cut } & \text { cycle, for } \\
& 10 \text { cycles }\end{array}$ \\
\hline
\end{tabular}

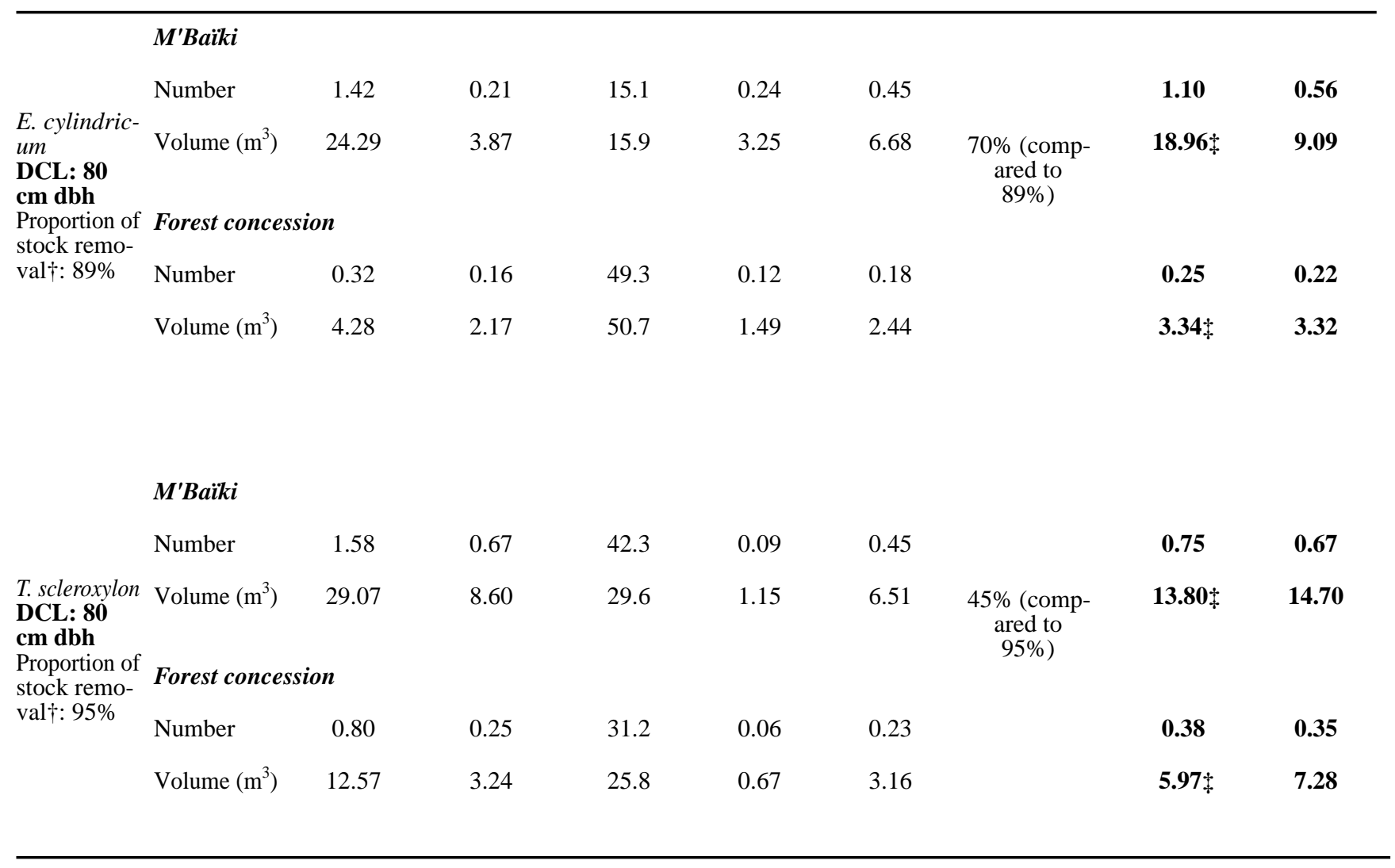

Note: The felling cycle is 30 years. Number of trees $\geq$ diameter cutting limit (DCL) and corresponding volumes are predictions made using a stochastic matrix model calibrated with data from the M'Baïki experimental site in the CAR (methods are described in Gourlet-Fleury et al. 2004, 2005). On this site, the two species were logged on $12 \mathrm{ha}$. Predictions were also made for a forest concession located in the CAR, using data from a management survey performed in 2004. Volume equations used were site specific.

$\dagger$ Percentage of the number of standing trees $\geq$ DCL in the forest.

$\neq$ Respectively, $78 \%$ (E. cylindricum) and $47 \%$ (T. scleroxylon) of the number of trees or volume harvested at first cut under the current felling regime. The sacrifice at first cut would thus be $22 \%(E$. cylindricum) and 53\% (T. scleroxylon) of the commercial volume. 
Fig. 2. Evolution of the number of exploitable trees under a repeated felling regime reproducing the parameters of the first logging: diameter cutting limit (DCL) $=80 \mathrm{~cm}$, logging intensity $=90 \%$ and $95 \%$ of the number of initial standing trees $\geq$ DCL for Entandrophragma cylindricum and Triplochiton scleroxylon, respectively, felling cycle $=30 \mathrm{yr}$. Recruitment among the smallest diameter class $(10 \mathrm{~cm}$ $\mathrm{dbh}$ ) was linked to the number of trees present in the largest diameter classes $(\geq 80 \mathrm{~cm}$ dbh for $E$. cylindricum and $\geq 60 \mathrm{~cm}$ dbh for T. scleroxylon).
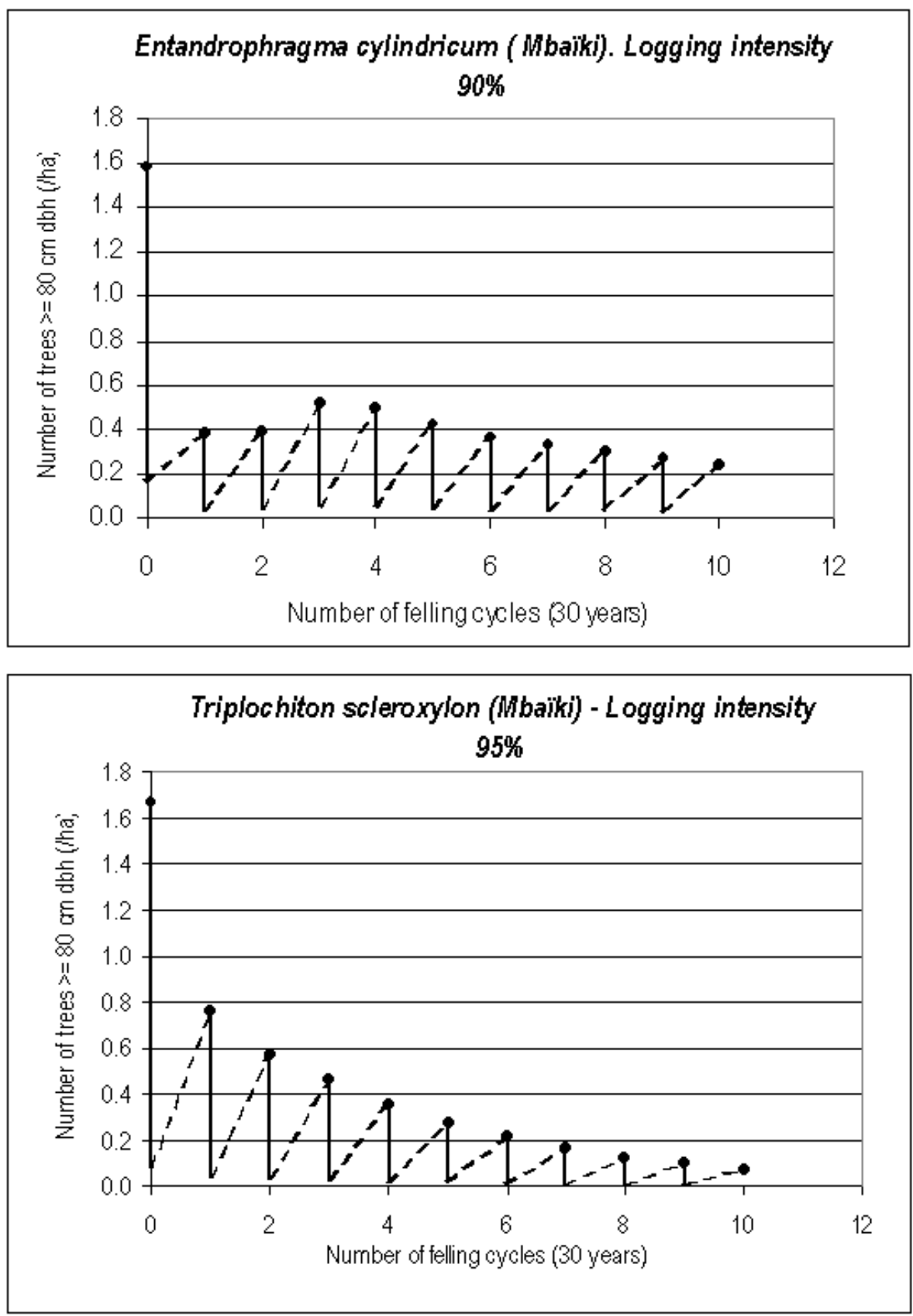
the presence of mother trees because of the time that has elapsed since seed dispersal. Thus, repeated felling of mother trees has uncertain consequences for recruitment. For our simulations, we linked recruitment into the $\geq 10 \mathrm{~cm}$ dbh class to the number of trees present in the largest diameter classes. We took into account both the diameter of fructification of the species studied and the minimum time needed for a seed to reach $10 \mathrm{~cm}$ in dbh to identify the threshold for the large diameter classes $(80 \mathrm{~cm}$ in dbh for E. cylindricum, $60 \mathrm{~cm}$ in $\mathrm{dbh}$ for $T$. scleroxylon).

\section{Do global disturbance levels endanger other species?}

Logging operations open the stands, increase light levels in all forest strata, and stimulate growth and recruitment into the $\geq 10 \mathrm{~cm}$ dbh class. They tend to either increase (E. cylindricum) or decrease $(T$. scleroxylon) mortality rates, depending on both the spatial pattern and degree of heliophily of the species. We accounted for these effects in our simulations, relying on data and behavior observed in the logged plots of M'Baïki. However, the applied logging intensities were high (4 trees/ha) compared to current practices because a large number of species were harvested, even though markets for them did not exist.

Such conditions greatly stimulated the population dynamics of light-demanding species, such as $E$. cylindricum and T. scleroxylon. Harvesting 1-2 trees/ha, as is currently done in most forest concessions of the Congo Basin, would probably not result in such dynamics; similar conclusions were reached by Fredericksen and Putz (2003), who emphasized that many valuable timber species in tropical forests cannot regenerate under low logging intensities. Felling the exploitable trees of $E$. cylindricum and T. scleroxylon while limiting the global opening of the stands would result in a rapid decrease in their populations. Matrix model simulations using parameters calibrated with data from undisturbed plots for these two species systematically showed quasi-extinction of the species within less than 10 cycles. This means that, when recommending a lower logging intensity for the species studied, we must assume that the global intensity of logging in the stand remains the same to keep it open. To achieve this, the logging effort should be distributed across a greater number of species or silvicultural operations should be undertaken after logging.

Although higher logging intensity does not appear to endanger the forest as a whole (Mbaro 2003, Gourlet-Fleury et al. 2004), the question of the longterm consequences of such regimes on the most shade-tolerant species remains unanswered. Gaining sustainable production of both heliophilous and shade-tolerant species while preserving most species in the stand may well be impossible. This leads to the question of what is preferable: (1) sustaining timber production for a larger range of species than today, based on rules defined with the help of models and allowing an unavoidable shift in floristic composition in dedicated areas; or (2) harvesting the whole available volume, then leaving with the hope that an efficient mechanism will protect it over the long term, as advocated by the proposed log-and-protect strategy (Rice et al. 2001).

\section{DISCUSSION: THE SUSTAINABILITY ISSUE}

Unlike Luckert and Williamson (2005), whose demonstration was for temperate forests, we argue that sustained yield and biodiversity conservation cannot be considered as fully distinct elements in tropical forests. However, as long as species are unlikely to reach extinction thresholds, sustainable yield of given species and sustainability of the socioeconomic development induced by industrial forestry must be clearly distinguished and specifically addressed.

\section{Spatial- and time-scale issues}

In terms of geographic distributions, there is no doubt that the number of harvestable trees of $E$. cylindricum and/or T. scleroxylon will decrease in forest concessions. In protected areas, the evolution may be slower (light-demanding species may be progressively supplanted by shade-tolerant species in areas where the forest is closing), even though the trend is similar. In addition, some forest areas will remain beyond the "profitability perimeter" (i. e., "the geographical point where their access and harvest costs depleted the entire value of [the] forest resource" [Hyde et al. 1996]) for some time; public roads could, however, quickly change the magnitude of such a perimeter. 
In the context of hyper-selective logging focused on light-demanding species, such as in remote forests of Central Africa, actual logging operations frequently (but not systematically) accelerate floristic changes that will occur in some forests, regardless of whether they are logged. Only an increase in overall logging intensity (with appropriate silvicultural measures and reducedimpact logging practices to lower subsequent mortality rates) through an increase in the number of species exploited would open the canopy enough to divert the forest from its likely path of change. However, this may also entail some difficulties for shade-tolerant species.

There is also the question of time scale. The fact that companies only focus on a narrow range of species in the Congo Basin is caused by timber market characteristics, which evolve over time. In Africa, logging has taken place for more than a century and the story remains the same. First, loggers focus on the one or two market-known species (e.g., mahogany Khaya ivorensis), and cut almost all the valuable trees within the area encompassed by the profitability perimeter (generally along the coastline, navigable rivers, or railways). When the targeted species become scarce, loggers offer their European retailers one or several "equivalent" species to replace the declining one. Because the initial cut was very selective, the loggers are able to re-enter the once-logged areas to harvest the next new species. [This is one reason why the log-and-protect strategy advocated by Rice et al. (2001), which is "the forest equivalent to 'dehorning the rhino,' where logging [is] of low intensity and [of] high value timber species" (Gullison 2003), can be considered biased by a static view of timber economics in a highly selective logging context. Removing the "cream" during the initial cut does not eliminate the financial value of the forest, but requires only new skills (industrial and marketing) and market evolution to add value to the remaining species (and the smallest diameter trees)]. This logging process has extended to remote forests with the expansion of infrastructure that widened the boundaries of the profitability perimeter (keeping in mind, however, that the number of species that can be harvested profitably diminishes with increases in transportation costs). The development of local efficient woodprocessing capacities also enlarges the profitability perimeter because the value added to production offsets the increase in transportation costs. Thus, new species that were formerly ignored become valuable for loggers and may be the basis of future logging cycles on previously logged areas.

\section{Economic issues}

Technical progress in wood processing, efficient commercial networks, and appropriate marketing all have the potential to allow this shift to new species. At the turn of the 20th century, nobody would have believed that any profit could be made in coastal African forests without including a large proportion of $K$. ivorensis or, in Gabon, okoumé (Aucoumea klaineana) in the harvest. K. ivorensis has become scarce nowadays, but has been replaced with other species. In the decades to come (i.e., over the next few cutting rotations), it seems unlikely that the forest industry will need the same proportion of E. cylindricum and/or T. scleroxylon as is required today to turn a profit. However, restricting the harvest today by $22-53 \%$ (figures suggested for both species in our case study) may force logging activities to grind to a halt because companies would probably be unable to replace the volumes lost with alternative species in the short term. In the intermediate term, one can hypothesize that market structure, technical progress, and the characteristics of companies will evolve and allow future loggers to rely on alternative species. Obviously, this is less a prediction than a mere possibility to be assessed against the (likely) possibility that companies may have to close down because of current restrictions on allowed volumes of key commercial species.

SFM, considered as the expression of sustainable development in a given sector, implies that the needs of both current and future generations are potentially satisfied. What will the needs of future generations be regarding tropical timber, let alone tropical forests? What proportion of today's harvested quantities of E. cylindricum or $T$. scleroxylon will the industry need to remain profitable over, say, the next 30,60 , or 100 years? Will the emerging schemes of payment for environmental services fulfill their promise in the future, making natural tropical forest logging incongruous? If so, is it worth placing a high level of short-term constraint, in terms of volume recovery rates, on the most exploited species? 


\section{The social dimension}

The social dimension of this issue is equally important. Industrial workers in the world's poorest countries rarely have a choice of job; it is in their interest, therefore, that timber activities remain sustainable to provide them with stable employment. Local populations using forest resources also generally have an interest in sustainable timber activities, provided that they can benefit from earmarked fiscal revenues, job opportunities, and social transfers organized through the concession system (cahier des charges) in countries where it exists. In the context of highly selective yields, the main risk for local populations is the growing scarcity of species, such as $E$. cylindricum, that produce goods used in the local economy, such as caterpillars, bark, oil, fruits, etc.

Few quantitative studies have been undertaken to verify whether highly selective logging practices in these low-population areas undermine the ability of local populations to meet their non-timber forest product (NTFP) needs. In the Congo Basin, notably in Cameroon, the case of moabi (Baillonella toxisperma) has been heralded as an example of the negative social impact of excessive logging focused on a single species that plays an important role in local livelihoods (Les Amis de la Terre 2005). However, it has been shown in Cameroon (Vermeulen and Doucet 2004) that the number of B. toxisperma trees needed to sustain a local Badjoué community NTFP economy is significantly smaller than the existing population of adult trees. Moreover, the rate of recovery of $B$. toxisperma after logging by a forest company operating in the same area is sufficient to fulfill the community's needs. Similar conclusions were reached by Eba'a Atyi (2000), who studied several species both logged for timber and used by villagers for NTFP in the area of Kribi, Cameroon.

\section{What thresholds, what trade-offs?}

Unlike in most temperate forests, it is impossible to separate yield and biodiversity issues in tropical forests; some commercial species are endemic, not very suitable for plantations, and thus, vulnerable. Promoting SFM entails acceptance of trade-offs between volume recovery of some species and forest economic rent that could be expected by the most efficient timber company in the short term (the capacity to re-create rents with a different yield composition takes time and is within the capability of only a few companies). But how can one evaluate the "acceptable" level of trade-off? Will it be possible to reach a consensus for, say, delivering forest certification?

Current criteria, such as those of the ATO/ITTO (2003), do not allow for much change in forest composition. Thus, they reflect a strong sustainability perspective that may be incompatible with the perpetuation of logging in the Congo Basin. The proposal for stabilized yield over time made in our numerical simulation in the Central African Republic, which allows only $47-78 \%$ recovery of the first-cut volume of E. cylindricum and $T$. scleroxylon, would probably be judged nonsustainable if one applies the ATO/ITTO (2003) criteria on a strict basis. If one assumes a more flexible interpretation, one could foresee the extreme difficulty or practical impossibility of reaching a consensus on an agreed-upon target recovery threshold that would be needed to certify the new logging practice as sustainable. This anticipated difficulty in achieving a consensus on such sensitive issues has probably to do with the fact that tropical certification is progressing very slowly (Rametsteiner and Simula 2003), and when it expands in some areas, it is challenged by environmental groups (see Counsell 1999, Freris and Laschefski 2001).

Uncertainty, a factor frequently used to explain difficulties encountered in evaluating the sustainability of activities such as tropical forest management, provides space for representation of conflicts reflecting personal and collective values, which are, by themselves, uneasy to reconcile (see Wang 2004). In scientific terms, some simple predictions have become increasingly easy to formulate, thanks to modeling and experiments, but the assessment of sustainability and the decision of what prescription to use remains fraught with difficulties; indeed, stakeholders have their own ideas of the balance among the three dimensions of sustainable development (social, economic, and ecological) and apply different implicit discount rates according to the situation. Because several companies operating in the Congo Basin are currently implementing forest management plans and are hoping to acquire certification within a couple of years, the coming debates are likely to be harsh, with major economic implications at the subregional level. Scientific results are likely to be mobilized by opposite-thinking stakeholders, who 
will derive very different conclusions from the same data. It is unlikely that these same stakeholders will agree upon species recovery thresholds after logging, inasmuch as the species targeted is not threatened by extinction.

\section{A few wise measures to be applied}

As discussed above, if logging intensity is increased in places where canopy openness is insufficient to ensure better regeneration of commercial lightdemanding species, some shade-tolerant species could become at risk, even though it is difficult to assess the risk. This risk must be alleviated at the regional scale through the design of a network of protected areas, as is partially the case in the Congo Basin. At the local scale, within management units, undisturbed areas should also be designated to preserve valuable habitats and serve as refuges for animals and seed sources for as great a number of species as possible.

Within production areas, where it is known that the forest structure will change, logging rules should be adapted to the real biological potentialities of the exploited species (Sist and Brown 2004) and reduced-impact logging methods implemented. Even if important gaps remain, a corps of knowledge exists that can help forest managers make objective decisions in this direction.

Moreover, one should not overlook well-targeted policy measures. Where global logging intensity is considered too low for the regeneration of commercial light-demanding species, the use of economic instruments to increase the profitability perimeter of less-used species could be helpful. Lowering taxes on abundant, but less-exploited species, such as limba/fraké (Terminalia superba), tali (Erythrophleum suaveolens), or agba/tola (Gossweilerodendron balsamiferum) in several Congo Basin countries, appears to be an appropriate incentive in this perspective, even if this represents only one limited fraction of the total cost. In the intermediate term, economic signals should be adjusted to foster the shift in species use expected from the industry.

\section{CONCLUSIONS}

The expansion of forest management plans, even if they are certified by a third party, will not remove doubts about their sustainability because the assessment of such quality depends on its conception; strong sustainability versus weak sustainability is a first major distinction that can be broken down into further, more subtle, distinctions. In this respect, the expression "sustainable forest management," when referring to exploitation under public authority-approved management plans, should be avoided, at least in research papers.

One merit of advocates of the log-and-protect strategy (Rice et al. 1997, Rice et al. 2001, Gullison 2003) is to have initiated the debate on the feasibility of sustainable logging of tropical forests with regard to long-term biodiversity conservation and economic profitability. These authors suggest a single selective cut, using reduced-impact logging methods, as early and fast as possible, to leave the remaining logged-over forest for full long-term conservation. This strategy has been criticized from an economic and socio-political perspective (Bulkan 2004, Karsenty 2004, Karsenty and Nasi 2004, Romero and Andrade 2004) and a silvicultural perspective (Pearce et al. 2003), but has reached a large international audience. Whatever one thinks of the log-and-protect strategy, one should acknowledge that translating the SFM paradigm into a silvicultural strategy is no easy task, especially when considering the issue of sustained yield of most currently exploited species. The simulation carried out on two typical species of the Congo Basin indicated that one possible way of stabilizing their yield over time is to decrease the rate of logging of the targeted species at first cut and increase the overall harvest intensity, i.e., cutting more less-used species using reduced-impact logging methods, to boost their renewal over time. In the Congo Basin, where current logging focuses on two or three species (Ruiz Pérez et al. 2005) and timber extraction rates per unit area are very low (1-2 trees/ ha for $8-12 \mathrm{~m}^{3}$ of commercial timber extracted in hinterlands), intensification of harvest strategies focusing on abundant and less-used species appears biologically viable for these species. However, it still must prove its economic feasibility to be viewed as sustainable. We argue that this shift in logging practices is likely to occur in the intermediate term, but is economically questionable in the short term. 
Embarking on such a path would entail a change in the structure and composition of exploited forests in the sub-region to meet the industry's current and future needs (including the assumption that the industry will be capable of reaching high standards of efficiency for giving value to currently less-used species) and to consolidate a local or national development based on the timber industry. On the other hand, protected areas, which have seemingly shown their effectiveness for the conservation of forest cover and structure (Bruner et al. 2001), will maintain a forest cover undisturbed by logging and constitute an alternative path for the evolution of large tracts of forest areas.

Could this potential change be qualified as coevolution between a managed ecosystem and a socio-economic sphere? In our sense, it might be, but one should recognize that the situation is still far from occurring in the regions mentioned. Forests under management plans still represent a minor proportion of the area devoted to logging; reentry on logged-over areas before the end of the legal felling cycle (mandatory rotation length) is frequent and small-scale unregulated logging is still spreading as a consequence of the socio-economic crisis. Another question deals with agriculture and population growth. Would the overall development pattern in these countries favor a Kuznet's curvelike path (with less reliance on land and natural resources, thanks to farming intensification), or will the current extensification trends continue? In any case, as long as the timber industry remains one of the rare activities able to raise significant revenue and employment in increasingly economically marginalized countries, endeavors in this direction appear worthy of support until credible global alternatives to natural forest exploitation emerge.

Responses to this article can be read online at:

http://www.ecologyandsociety.org/voll1/iss 1/art26/responses/

\section{Acknowledgments:}

The data used in this paper came from the M'Baïki site, and from a forest concession managed with the help of the "Projet d'Appui à la Réalisation des Plans d'Aménagement Forestier" (PARPAF) in the Central African Republic. The M'Baiki site is managed by the "Institut Centrafricain de la Recherche Agronomique” (ICRA) and the
"Ministère des Eaux, Forêts, Chasse, Pêche, chargé de l'Environnement" (MEFCPE) of the CAR, with the help of the Forest Department of CIRAD, and is funded by the centrafrican forest fund and the French Ministry of Foreign Affairs. PARPAF is funded by the French Ministry of Foreign Affairs.

\section{LITERATURE CITED}

African Timber Organization and International Tropical Timber Organization. 2003. ATO/ITTO principles, criteria and indicators for the sustainable management of African natural tropical forests. ITTO Policy Development Series, Number 14. [online] URL: http://www.itto.or.jp/live/Live S erver/155/ps14e.pdf.

Bawa, K. S., and R. Seidler. 1998. Natural forest management and conservation of biodiversity in tropical forests. Conservation Biology 12(1):45-55.

Bedel, F., L. Durrieu de Madron, B. Dupuy, V. Favrichon, H.-F. Maître, A. Bar-Hen, and P. Narboni. 1998. Dynamique de croissance dans des peuplements exploités et éclaircis de forêt dense africaine. Dispositif de M'Baïki en République Centrafricaine (1982-1995). Série FORAFRI, Numero 1. CIRAD-Forêt, Montpellier, France.

Bruner, A. G., R. E. Gullison, R. E. Rice, and G. A. B. da Fonseca. 2001. Effectiveness of parks in protecting tropical biodiversity. Science 291:125-128.

Bulkan, J. 2004. Reply to Niesten and Rice's comment. International Forestry Review 6 (1):61-63. [online] URL: http://www.extenza-eps.com/ CFA/doi/abs/10.1505/ifor.6.1.61.32063.

Connell, J. H. 1978. Diversity in tropical rainforests and coral reefs. Science 199:1302-1310.

Counsell, S. 1999. Trickery or truth? An examination of the effectiveness of the forest stewardship council. The Rainforest Foundation, London, UK.

Eba'a Atyi, R. 2000. TROPFOMS, a decision support model for sustainable management of South-Cameroon's rain forests. TropenbosCameroon Series, Number 2. Tropenbos Foundation, Kribi, Cameroon. 
Fredericksen, T. S., and F. E. Putz. 2003. Silvicultural intensification for tropical forest conservation. Biodiversity and Conservation 12:1445-1453.

Freris, N., and K. Laschefski. 2001. Seeing the wood from the trees. Ecologist 31(6). [online] URL: http://www.wald.org/fscamaz/fsc eco2.pdf.

Gourlet-Fleury, S., V. Favrichon, L. Schmitt, and P. Petronelli. 2004. Consequences of silvicultural treatments on stand dynamics at Paracou. Pages 254-280 in S. Gourlet-Fleury, J.-M. Guehl, and O. Laroussinie, editors. Ecology and management of a neotropical rainforest. Lessons drawn from Paracou, a long-term experimental research site in French Guiana. ECOFOR and Elsevier, Paris, France.

Gourlet-Fleury, S., G. Cornu, S. Jésel, H. Dessard, J.-G. Jourget, L. Blanc, and N. Picard. 2005. Using models for predicting recovery and assessing tree species vulnerability in logged tropical forests: a case study from French Guiana. Forest Ecology and Management 209(1-2):69-86.

Gullison, R. E. 2003. Does forest certification conserve biodiversity. Oryx 37(2):153-165. [online] URL: http://www.yale.edu/forestcertification/ pdfs/03 oryx certification.pdf.

Hyde, W. F., G. S. Amacher, and W. Magrath. 1996. Deforestation and forest land use: theory, evidence, and policy implications. World Bank Research Observer 11(2):223-248.

Karsenty, A. 2004. Des rentes contre le développement? Les nouveaux instruments d'acquisition mondiale de la biodiversité et l'utilisation des terres dans les pays tropicaux. Mondes en Développement 127:61-74.

Karsenty, A., and R. Nasi. 2004. Les concessions de conservation sonnent-elles le glas de l'aménagement forestier durable? Revue Tiers Monde 177:153-162.

Les Amis de la Terre. 2005. Moabi: arbre de vie ou de profit? Les Amis de la Terre. [online] URL: http://www.amisdelaterre.org/IMG/pdf/ doccampagnemoabi.pdf.

Luckert, M. K., and T. Williamson. 2005. Should sustained yield be part of sustainable forest management? Canadian Journal of Forest Research 35:356-364.

Mbaro, T. 2003. Effets des traitements sylvicoles sur la structure et la dynamique des peuplements forestiers du dispositif de Mbaïki en RCA. Mémoire de DSPU. ENGREF-CIRAD, Montpellier, France.

Molino, J.-F., and D. Sabatier. 2001. Tree diversity in tropical rain forests: a validation of the intermediate disturbance hypothesis. Science 294:1702-1704.

Pearce, D., F. E. Putz, and J. K. Vanclay. 2003. Sustainable forestry in the tropics: panacea or folly? Forest Ecology and Management 172(2-3):229-247. [online] URL: http://dx.doi.org/10.1016/S0378-1127 (01)00798-8.

Poore, D., P. Burgess, J. Palmer, S. Rietbergen, and T. Synnott. 1989. No timber without trees. Earthscan, London, UK.

Rametsteiner, E., and M. Simula. 2003. Forest certification - an instrument to promote sustainable forest management? Journal of Environmental Management 67(1):87-98. [online] URL: http://dx. doi.org/10.1016/S0301-4797(02)00191-3.

Rice, R. E., R. E. Gullison, and J. W. Reid. 1997. Can sustainable management save tropical forests? Scientific American 276:44-49.

Rice, R. E., C. A. Sugal, S. M. Ratay, and G. A. B. da Fonseca. 2001. Sustainable forest management: a review of conventional wisdom. Advances in Applied Biodiversity Science, Number 3. CABS/Conservation International, Washington, D.C., USA. [online] URL: http://www.cid.harvard. edu/esd/events/Rice, \%20et\%20al\%20SFM.pdf.

Romero, C., and G. I. Andrade. 2004. Letters: 3. Conservation Biology 18(6):1454-1455. [online] URL: http://dx.doi.org/10.1111/j.1523-1739.2004.1 858 3.X.

Ruiz Pérez, M., D. E. de Blas, R. Nasi, J. A. Sayer, M. Sassen, C. Angoué, N. Gami, O. Ndoye, G. Ngono, J.-C. Nguinguiri, D. Nzala, B. Toirambe, and Y. Yalibanda. 2005. Logging in the Congo Basin: a multi-country characterization of timber companies. Forest Ecology and Management 214 (1-3):221-236. [online] URL: http://dx.doi.org/10.1 
016/j.foreco.2005.04.020.

Sist, P., and N. Brown. 2004. Silvicultural intensification for tropical forest conservation: a response to Fredericksen and Putz. Biodiversity and Conservation 13:2381-2385. [online] URL: http://d x.doi.org/10.1007/s10531-004-0389-5.

Vermeulen, C., and J.-L. Doucet. 2005. Conservation and sustainable use of non-timber forest products in favour of local communities within integrated forest management in Central Africa. Pages 267-280 in M. de Dapper, editor. International symposium: tropical forest in a changing global context. Royal Academy of Overseas Sciences, UNESCO (MAB), Brussels, Belgium. [online] URL: http://www.kaowarsom.be

Wang, S. 2004. One hundred faces of sustainable forest management. Forest Policy and Economics 6 (3-4):205-213. [online] URL: http://dx.doi.org/10.1 016/j.forpol.2004.03.004. 